Article

\title{
Investigating Nutritional Behavior and Oral Health Habits among Adults and Children in North-Eastern Greece
}

\author{
Alexandra Melissari ${ }^{1, *}$, Athanasios Alexopoulos ${ }^{1} \mathbb{D}$, Ioanna Mantzourani ${ }^{1}$, Stavros Plessas ${ }^{1} \mathbb{D}$, \\ Chrissoula Voidarou ${ }^{2}$ (D) Christina Tsigalou ${ }^{3}$ and Eugenia Bezirtzoglou ${ }^{4, *(D)}$ \\ 1 Laboratory of Microbiology, Biotechnology and Hygiene, Department of Agricultural Development, \\ Democritus University of Thrace, 68200 Orestiada, Greece; alexopo@agro.duth.gr (A.A.); \\ imantzou@agro.duth.gr (I.M.); splessas@agro.duth.gr (S.P.) \\ 2 Department of Public Health, Region of Epirus, 47100 Arta, Greece; xvoidarou@yahoo.gr \\ 3 Department of Medicine, Democritus University of Thrace, Alexandroupolis University Hospital \\ Microbiology Laboratory, 68100 Alexandroupolis, Greece; xtsigalo@med.duth.gr \\ 4 Laboratory of Hygiene and Environmental Protection, Department of Medicine, Democritus University of \\ Thrace, 68100 Alexandroupolis, Greece \\ * Correspondence: melissarialex@hotmail.com (A.M.); empezirt@yahoo.gr (E.B.)
}

check for updates

Citation: Melissari, A.; Alexopoulos, A.; Mantzourani, I.; Plessas, S.; Voidarou, C.; Tsigalou, C.;

Bezirtzoglou, E. Investigating

Nutritional Behavior and Oral Health Habits among Adults and Children in North-Eastern Greece. Oral 2021, 1, 56-74. https://doi.org/10.3390/ oral1020007

Academic Editor: Rachel Tham

Received: 6 January 2021

Accepted: 22 March 2021

Published: 2 April 2021

Publisher's Note: MDPI stays neutral with regard to jurisdictional claims in published maps and institutional affiliations.

Copyright: (c) 2021 by the authors. Licensee MDPI, Basel, Switzerland. This article is an open access article distributed under the terms and conditions of the Creative Commons Attribution (CC BY) license (https:// creativecommons.org/licenses/by/ $4.0 /)$.

\begin{abstract}
The importance of the oral microbiota is strictly linked to global human health. When imbalance of the oral microbiota occurs, and it is characterized by shifts in bacterial composition and diversity; a state called dysbiosis is settled. There is an increasing amount of scientific evidence that this condition is associated with oral diseases caries, gingivitis and periodontitis. Diet seems to be a key factor for oral and dental health, impacting upon the oral microbiota. In an attempt to clarify the role of diet, as well as other implicating risk factors predisposing to oral disease, in the present study we enrolled an urban area of north-eastern Greece. Socio-demographical as well as hygienic and nutritional habits of a target group consisting of adult and children were entered in our study through a survey. People of the studied area are less interested in preventive and other dental therapies. Children and adults are less interested in healthy eating, yet they often consume sugary foods and often outside of their main meal. The partial shifting to the standard of the Mediterranean diet and less to the standard of the western type foods is notable. It is important to raise the awareness of both children and adults through strategical campaigns and education on oral health, oral hygiene and the benefits of a balanced diet.
\end{abstract}

Keywords: oral health; dental health; disease; diet; nutrition; health habits; hygiene; questionnaire; children nutrition

\section{Introduction}

The human body constitutes a composite network which is characterized by permanent interconnection and provides interesting aspects in the pathogenesis of multiple diseases [1,2]. Recent scientific data reported the importance of oral health for overall health [3,4]. New breakthroughs in technological approaches encompassing genome sequencing methodologies shed more light on the identification of the human microbiotas and their role $[4,5]$.

Oral health is considered an integral part of general health as well as quality of life [6-8]. The most common oral diseases are caries and periodontal diseases $[9,10]$, complex diseases of infectious nature, which are caused by the imbalance between the host and the host microorganisms of the biofilm in the oral cavity [11]. Caries and periodontal disease are multifactorial $[4,12]$. Both diseases present common risk factors, however with different pathophysiology. The most common risk factor for both diseases is nutritional and is related to fermentable carbohydrates, however their mechanisms are different [13]. 
Other common risk factors for caries and periodontitis are decreased salivary flow [14], rheumatoid arthritis [15], smoking [12], diabetes mellitus [16], mostly undiagnosed or uncontrolled, and obesity $[17,18]$.

Occurrence of dental disease has been registered to be as high as $90 \%$ of the global population [19]. Edentulism following periodontal disease showed high prevalence in upper middle-income countries compared to high-income countries [19]. Differences in prevalence seem to be tightly related to hygienic habits, underlying non-treated disease, socio-economic conditions and national oral health public system-associated strategies [19]. Edentulism is also reported in old age [20] due to multiple age-related pathologies in frail elderly people.

Nutrition is closely related to oral health [21]. The World Health Organization (WHO) states the importance of malnutrition in global health [22]. Malnutrition equally includes under and over nutrition [22]. While over-nutrition is associated to metabolic disorders and diabetes, undernutrition seems to be associated to inchoate development of oral tissues and cavity [23]. Diet can induce shifts in the oral and gastrointestinal microbiota [24-26]. The profile of the oral microbiome used to identify microbial taxa is related to oral diseases by integrated analysis and host genome/omics information was evaluated in the frame of a global study [5]. Divergence in species diversity between saliva and plaque was observed to increase with dental disease severity [5]. Saliva seems to influence the maintenance of a healthy oral microbiota [5]. As is known, oral plaque upon fermentable carbohydrate intake is characterized by a rapid $\mathrm{pH}$ decrease impacting on the oral microbiota [27], which is a dynamic system with interconnected metabolic networks and activities in space and time [2]. While $\mathrm{pH}$ decrease after a sugar intake has been known for 80 years already [28], recent research with in vivo and in vitro studies showed that this $\mathrm{pH}$ decrease is not, as thought, exclusively related to Lactobacillus acidophilus and Streptococcus mutans but to the global microbiota species that induce excess acid production and tooth demineralization [29].

Oral Health Related Quality Of Life (OHRQOL) is a concept developed by the WHO around 30 years ago, yet it still remains relevant [30]. Since then, multiple conceptual models of improved OHRQOL were developed [31,32], recommending the need for oral health to be appropriately defined as a system contributing to total health; the various variables influencing oral health outcomes need to be thoughtfully considered and methodological issues such as sensitivity, specificity, should properly addressed [33].

However, periodontal disease and dental caries did not match as classic clinical indicators of oral diseases for this new approach of health, as social-demographic issues and living status impact global health [33]. Globally, all the above scientific teams agreed that the absence of perceived need was the main reason for not visiting the dentist [34]. Alternatively, scientists tried to include all different parameters in the form of questionnaires [34].

From another aspect, oro-dental disease services are costly [35], especially when long untreated [36]. It is reported that the cost for treatment of dental caries exceeds those of treating cancer, osteoporosis and cardio-vascular diseases. The total economic burden of dental services expenditures remains as high as $10 \%$ of the total health services in developing as well as developed countries [37].

In this frame, our study aimed to clarify risk associated factors predisposing to oral disease based on health, socio-demographical and nutritional habits of adult and child populations in rural and urban Greece.

\section{Material and Methods}

A total of 576 people were enrolled in our study including 186 children and 390 adults.

As there is no standard questionnaire to assess oral health, we aimed to design an appropriate questionnaire for assessing oral health status in our target population. The questionnaire was designed for both groups: (a) children (completed by the aid of their parents) (Table 1) and (b) adults (Table 2) and distributed to a random sample of these populations. After explanatory discussion with the participants, the questionnaires were fulfilled and collected by us. As stated, questionnaires were completed exclusively by 
Children's parents for the very young age (up to 8 years old) and thereafter from 9 to 17 years old in collaboration with the child. We secured anonymity as required by ethical issues as no name or identification data were reported on the questionnaires.

Table 1. Age range and gender in the children group.

\begin{tabular}{cccc}
\hline \multirow{2}{*}{ Age Range } & \multicolumn{2}{c}{ Sex } & \multirow{2}{*}{ Total } \\
\cline { 2 - 3 } & Male & Female & \\
\hline 1-4 years & $1(1.01 \%)$ & $1(1.01 \%)$ & $2(1.08 \%)$ \\
5-8 years & $12(12.12 \%)$ & $15(17.24 \%)$ & $27(14.52 \%)$ \\
9-12 years & $38(38.38 \%)$ & $31(35.63 \%)$ & $69(37.10 \%)$ \\
13-17 years & $48(48.48 \%)$ & $40(45.98 \%)$ & $88(47.31 \%)$ \\
Total & $99(100.0 \%)$ & $87(100.0 \%)$ & $186(100.0 \%)$ \\
\hline
\end{tabular}

Table 2. Age range and gender in the adult group.

\begin{tabular}{cccc}
\hline \multirow{2}{*}{ Age Range } & \multicolumn{2}{c}{ Sex } & \multirow{2}{*}{ Total } \\
\cline { 2 - 3 } & Male & Female & \\
\hline 18-24 years & $20(13.51 \%)$ & $46(19.09 \%)$ & $66(16.97 \%)$ \\
$25-34$ years & $25(16.89 \%)$ & $27(11.20 \%)$ & $52(13.37 \%)$ \\
$35-40$ years & $14(9.46 \%)$ & $23(9.54 \%)$ & $37(9.51 \%)$ \\
$41-49$ years & $34(22.97 \%)$ & $56(23.24 \%)$ & $90(23.14 \%)$ \\
$>50$ years & $55(37.16 \%)$ & $89(36.93 \%)$ & $144(37.02 \%)$ \\
Total & $148(100.0 \%)$ & $241(100.0 \%)$ & $389(100.0 \%)$ \\
\hline
\end{tabular}

Our study was exclusively based on questionnaires and no clinical examination was performed in our target groups. Caries prevalence was calculated based on the percentage of positive cases and no Decay, Missing, Filled, Teeth (DMFT) and Significant Caries Index $(\mathrm{SiC})$ clinical caries index was calculated as physical clinical examination was not performed.

Considering our objectives, the questionnaire was focused basically on perceiving oral health daily habits (brushing, mouth washing, flossing), oral health medical services (dental check-up at least once a year), oral diseases (gingivitis, periodontitis) and nutritional preferences (consumption of meat, milk, vegetables, fish, fruits, sugar or sugar substitutes, juices, soft drinks, energy drinks, spicy foods, water, gums). In this vein, responses were given in dichotomous questions, as well as multiple choice questions. Results were based on the answer to each specific question. Questionnaire qualitative and quantitative validity was explored initially by a group of university professors with experience in epidemiological and public health issues and later by 10 children with their parents who belong to the non-academic personnel of the department.

The target population includes participants living in the urban Evros areas (Alexandroupolis, Didymoteicho, Orestiada, Soufli). According to the 2011 census the population in Evros prefecture was 147,947. Based on a representative sample size [38] with a 50\% population variance, $95 \%$ confidence level and 5 as a margin of error would involve at least 384 participants [39]. Respondents were approached in a random manner in public places (local markets, bus stops, schools during the pick-up time). Approximately 2 out of 10 individuals showed willingness to participate in the study. Finally, minors or their guardians with intellectual limitations which may impede correct understanding of the questionnaire were excluded.

\section{Statistical Evaluation}

We tabulated the data provided by our questionnaires and proceeded with calculations by the use of MS Excel 2010 version 14.0 (Microsoft Corporation, Redmond, WA, USA). We performed statistical analysis (descriptive quantitative research) by the use of SPSS 
Statistics software version 22.0 (IBM Corp. Released 2013. IBM SPSS Statistics for Windows, Version 22.0. Armonk, NY, USA) at a 95\% confidence interval.

\section{Ethics}

According to article 21 of Greek law 4521/2018 based on the Regulation (EU) 2016/679 of the European Parliament and of the Council of 27 April 2016 and according Directive 95/46/EC (General Data Protection Regulation) each Higher Educational Institute established and operates a Committee on Research Ethics (EHDE).

Since this study was completed before 2018 no approval from the EHDE was required, although all measures were taken to ensure the privacy of respondents (minors and adults). During the survey no data leading to the identification of any person were collected, no physical examination occurred, and minors always accompanied by their guardians.

\section{Results}

As stated, results of the questionnaires were evaluated based in each specific question. Results for each studied group population (adults and children) were evaluated separately.

Typical demographic and socio-economic characteristics, general health and oral health status as well as idiosyncratic behavioral habits and attitudes in items of oral health and nutritional preferences were evaluated. The resulting characteristics of the above were accompanied by useful correlations.

\subsection{Demographics of the Studied Group}

As stated, from the demographic data in Section 2 Material and Methods (Table 1), the sample size of children involved in the study was 186 children of which 99 were males (53.2\%) and 87 were females (46.8\%) aged from 1 to 17 years old. Questionnaires were completed exclusively by children's parents for the very young age (up to 8 years old) and thereafter from 9 to 17 years old in collaboration with the child. Concerning the adult group, demographic data (Table 2) of 389 adults are reported; 148 males (38.1\%), 241 females $(61.9 \%)$, from 18 to 60 years old participated in our study.

\subsection{Frequency and Type of Consumed Food by the Studied Group}

In Table 3 the results of our research on the eating habits of the children group are presented. Most children involved in the study consume daily dairy products $73.1 \%$ $(n=133)$ and fruits $47.3 \%(n=86)$, in contrast with low meat consumption $5.5 \%(n=10)$ and rare fish consumption $0.6 \%(n=1)$. Fishes are consumed usually once a week by a $50.8 \%(n=92)$ and meat $2-3$ times per week by $66.5 \%(n=121)$. However, a considerable number of them $(32.8 \%, n=59)$ consume foods rich in sugars daily.

Table 3. Frequency and type of foods and drinks consumed by children.

\begin{tabular}{cccccc}
\hline Type of Food & Daily & 2-3 Times a Week & Once a Week & Once a Month & None \\
\hline Soft drinks & $13(7.2 \%)$ & $30(16.6 \%)$ & $29(16 \%)$ & $39(21.5 \%)$ & $70(38.7 \%)$ \\
Dairy products & $133(73.1 \%)$ & $37(20.3 \%)$ & $8(4.4 \%)$ & $1(0.5 \%)$ & $3(1.6 \%)$ \\
Meat & $10(5.5 \%)$ & $121(66.5 \%)$ & $47(25.8 \%)$ & $3(1.6 \%)$ & $1(0.5 \%)$ \\
Vegetables & $4(35.2 \%)$ & $72(39.6 \%)$ & $19(10.4 \%)$ & $6(3.3 \%)$ & $21(11.5 \%)$ \\
Nuts & $7(14.9 \%)$ & $36(19.9 \%)$ & $47(26 \%)$ & $32(17.7 \%)$ & $39(21.5 \%)$ \\
Foods rich in sugar & $59(32.8 \%)$ & $69(38.3 \%)$ & $36(20 \%)$ & $5(2.8 \%)$ & $11(6.1 \%)$ \\
Fruits & $86(47.3 \%)$ & $59(32.4 \%)$ & $19(10.4 \%)$ & $4(2.2 \%)$ & $14(7.7 \%)$ \\
Fishes & $1(0.6 \%)$ & $18(9.9 \%)$ & $92(50.8 \%)$ & $41(22.7 \%)$ & $29(16 \%)$ \\
Fast Food & $4(2.2 \%)$ & $33(18.2 \%)$ & $63(34.8 \%)$ & $52(28.7 \%)$ & $29(16 \%)$ \\
\hline
\end{tabular}

As shown in Table 4, adults in the study consume vegetables $(52.9 \%, n=202)$, fruits $(48.4 \%, n=185)$ and dairy products $(51.6 \%, n=197)$ daily, in contrast with low meat consumption $(8.5 \%, n=33)$ and rare fish consumption $(0.5 \%, n=2)$. Fishes are usually 
consumed once a week by $62.8 \%(n=241)$ and meat $2-3$ times per week $(35.1 \%, n=134)$.

Foods rich in sugars were consumed daily $(27.6 \%, n=105)$ by the adult group.

Table 4. Frequency and type of foods and drinks consumed by adults.

\begin{tabular}{cccccc}
\hline Type of Food & Daily & 2-3 Times a Week & Once a Week & Once a Month & None \\
\hline Soft drinks & $13(3.4 \%)$ & $50(13.1 \%)$ & $70(18.3 \%)$ & $80(20.9 \%)$ & $169(44.2 \%)$ \\
Dairy products & $197(51.6 \%)$ & $134(35.1 \%)$ & $32(8.4 \%)$ & $7(1.8 \%)$ & $12(3.1 \%)$ \\
Meat & $33(8.5 \%)$ & $258(66.3 \%)$ & $81(20.8 \%)$ & $10(2.6 \%)$ & $7(1.8 \%)$ \\
Vegetables & $202(52.9 \%)$ & $141(36.9 \%)$ & $25(6.5 \%)$ & $9(2.4 \%)$ & $5(1.3 \%)$ \\
Nuts & $57(14.7 \%)$ & $113(29.1 \%)$ & $96(24.7 \%)$ & $73(18.8 \%)$ & $49(12.6 \%)$ \\
Foods rich in sugar & $105(27.6 \%)$ & $129(33.9 \%)$ & $73(19.2 \%)$ & $46(12.1 \%)$ & $27(7.1 \%)$ \\
Fruits & $185(48.4 \%)$ & $120(31.4 \%)$ & $42(11 \%)$ & $27(7.1 \%)$ & $8(2.1 \%)$ \\
Fishes & $2(0.5 \%)$ & $47(12.2 \%)$ & $241(62.8 \%)$ & $81(21.1 \%)$ & $13(3.4 \%)$ \\
Fast food & $3(0.8 \%)$ & $45(11.8 \%)$ & $101(26.4 \%)$ & $134(35.1 \%)$ & $99(25.9 \%)$ \\
\hline
\end{tabular}

In an attempt to evaluate the possible influence of residence of children with their oral health, we collected data from the questionnaires on their permanent residence comparing the urban Evros area to the other urban areas in Greece.

\subsection{Oral Health Status of the Studied Group}

It is reported (Table 5$)$ that only $18.8 \%(n=34)$ of the total studied children residing in the urban Evros area had no oral disease, while dental caries $(6.1 \%, n=11)$, gingivitis $(1.1 \%, n=2)$ and periodontitis $(5.5 \%, n=10)$ were observed (Table 5$)$. Children residing in other urban areas showed no oral disease $(41.4 \%, n=75)$, while dental caries $(21.5 \%$, $n=39)$, gingivitis $(5.0 \%, n=9)$ and periodontitis $(6.1 \%, n=11)$ were found to be increased.

Table 5. Place of residence of children (Evros/other areas) in relation to the condition of oral health.

\begin{tabular}{cccc}
\hline & Residence Evros & Other Urban Areas & Total \\
Oral Health Status & Urban Area & N (\%) & N (\%) \\
\hline Absence of oral pathol ogy & $34(18.8 \%)$ & $75(41.4 \%)$ & $109(60.2 \%)$ \\
Dental Caries & $11(6.1 \%)$ & $39(21.5 \%)$ & $50(27.6 \%)$ \\
Gingivitis & $2(1.1 \%)$ & $9(5.0 \%)$ & $11(6.1 \%)$ \\
Periodontitis & $10(5.5 \%)$ & $11(6.1 \%)$ & $21(11.6 \%)$ \\
\hline Total & $56(30.9 \%)$ & $56(30.95)$ & $125(69.1 \%)$ \\
\hline
\end{tabular}

a Percentages and totals are based on respondents.

Only $18.6 \%(n=70)$ of the total studied adults residing in the Evros urban area had no oral disease, while dental caries $(3.2 \%, n=12)$, gingivitis $(4.0 \%, n=15)$ and periodontitis $(1.3 \%, n=5)$ were observed (Table 6$)$. Adults residing in urban areas showed no oral disease $(39.5 \%, n=149)$, while dental caries $(8.8 \%, n=33)$, gingivitis $(4.0 \%, n=15)$ and periodontitis $(1.3 \%, n=5)$ were found to be increased. Moreover, in adults, orthodontic anomalies $(1.6 \%, n=6)$ and edentulism $(9.5 \%, n=36)$ were reported. 
Table 6. Place of urban residence of adults (Evros/other areas) in relation to the condition the oral health.

\begin{tabular}{cccc}
\hline Oral Health Status & Residence Evros & Other Urban Areas & Total \\
Urban Area & N (\%) & (\%) & N (\%) \\
\hline Absence of oral pathology & $70(18.6 \%)$ & $149(39.5 \%)$ & $219(58.1 \%)$ \\
Dental Caries & $12(3.2 \%)$ & $33(8.8 \%)$ & $45(11.9 \%)$ \\
Gingivitis & $15(4.0 \%)$ & $43(11.4 \%)$ & $58(15.4 \%)$ \\
Periodontitis & $5(1.3 \%)$ & $14(3.7 \%)$ & $19(5.0 \%)$ \\
Orthodontic anomaly & $6(1.6 \%)$ & $14(3.7 \%)$ & $20(5.3 \%)$ \\
Edentulism * & $36(9.5 \%)$ & $38(10.1 \%)$ & $74(19.6 \%)$ \\
Total & $128(34.0 \%)$ & $128(34.0 \%)$ & $249(66.0 \%)$ \\
\hline
\end{tabular}

a Group; percentages and totals are based on respondents. ${ }^{*}$ the clinical word for being wholly or partially toothless or having one or more missing teeth.

\subsection{Nutritional Habits of the Studied Group}

Children's habits are presented in Figures 1-7. In Figure 1, only 44\% $(n=80)$ of the children express an interest in healthy eating and its application, while the remainder seem not to be interested in healthy eating $(36.8 \%, n=67)$ or find it difficult to implement $(19.2 \%$, $n=35)$.

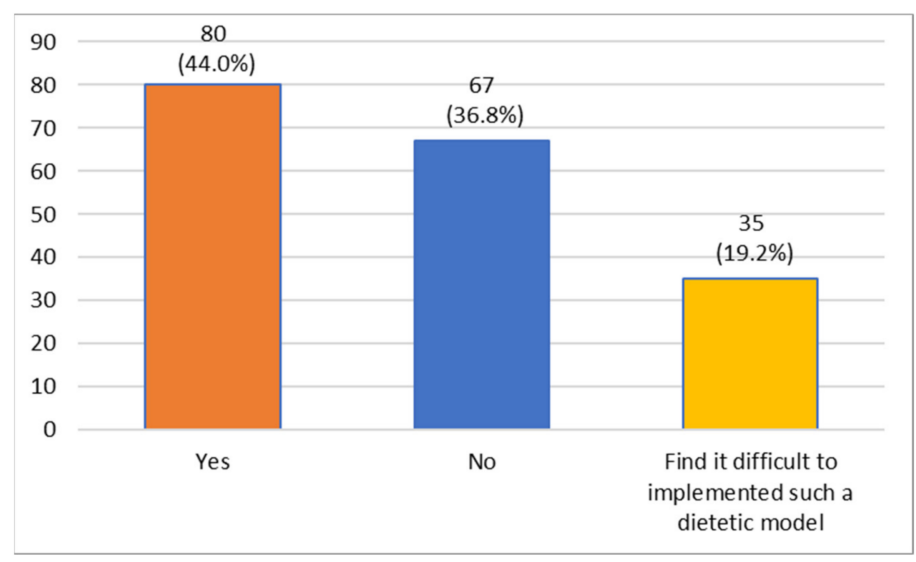

Figure 1. Distribution of the answers given by children regarding healthy eating.

Only 3.3\% $(n=6)$ of the children expresses an interest in vegetarian diet, while $96.7 \%$ $(n=176)$ seem to not be interested in such a diet (Figure 2).

Most of the children $(79.8 \%, n=142)$ choose their food mostly following their preferences (i.e., everything they want) while the remaining seem to choose food based on their health problems $(3.9 \%, n=7)$ or to prevent future health problems $(11.8 \%, n=21)$ (Figure 3).

As can be seen from Figure 4, children consume food products following the buying habits of their parents, almost exclusively from local producers $(10.4 \%, n=19)$, supermarkets $(72 \%, n=131)$, or both $(17.6 \%, n=32)$.

A total of $28.9 \%(n=52)$ of the children express an interest in organic foods while most of them $(38.9 \%, n=70)$ or rarely $(32.2 \%, n=58)$ do not consume such foods (Figure 5$)$. 


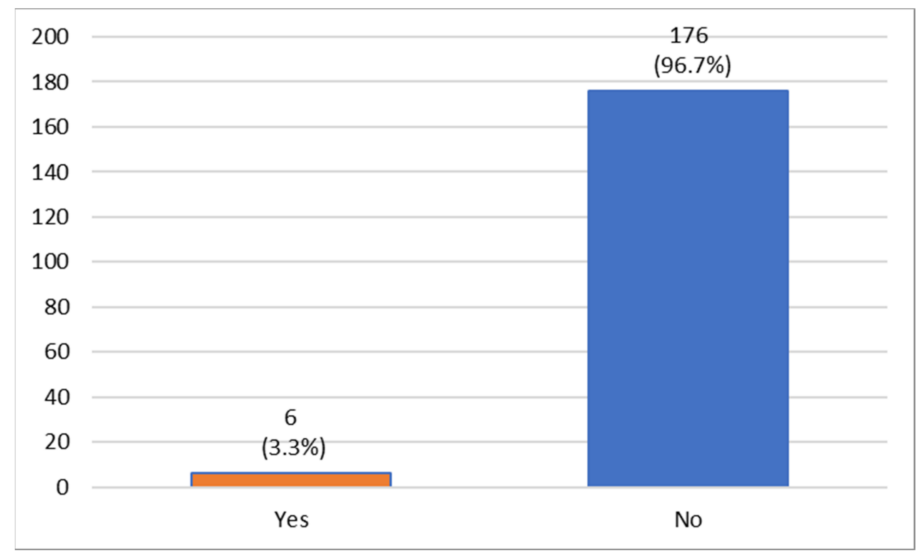

Figure 2. Distribution of the answers given by children regarding vegetarian diet.

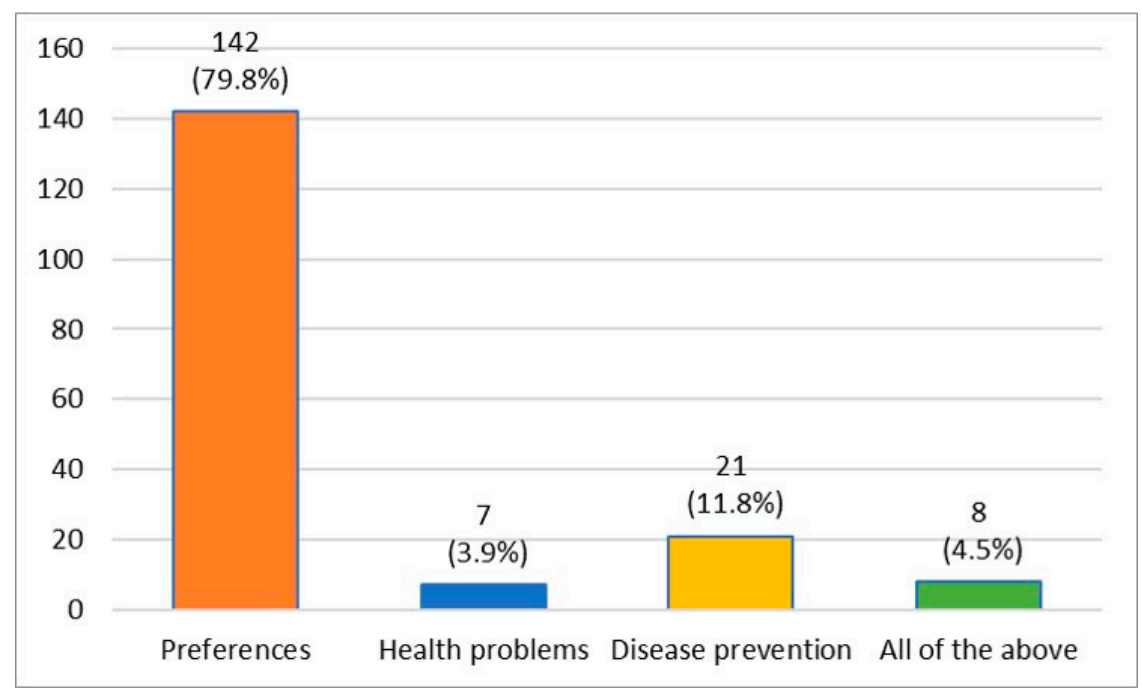

Figure 3. Distribution of the answers given by children regarding food selection.

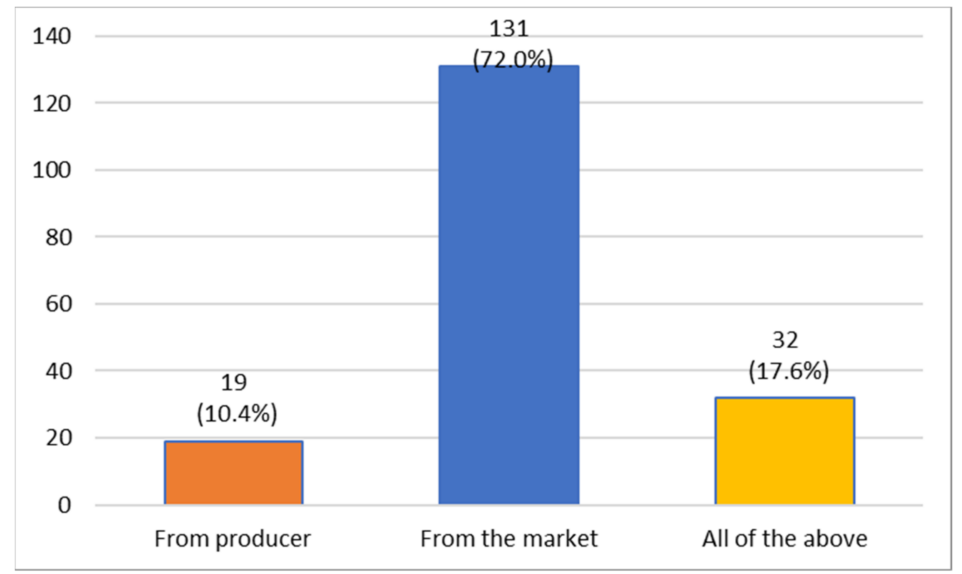

Figure 4. Distribution of the answers given by children regarding food purchased. 


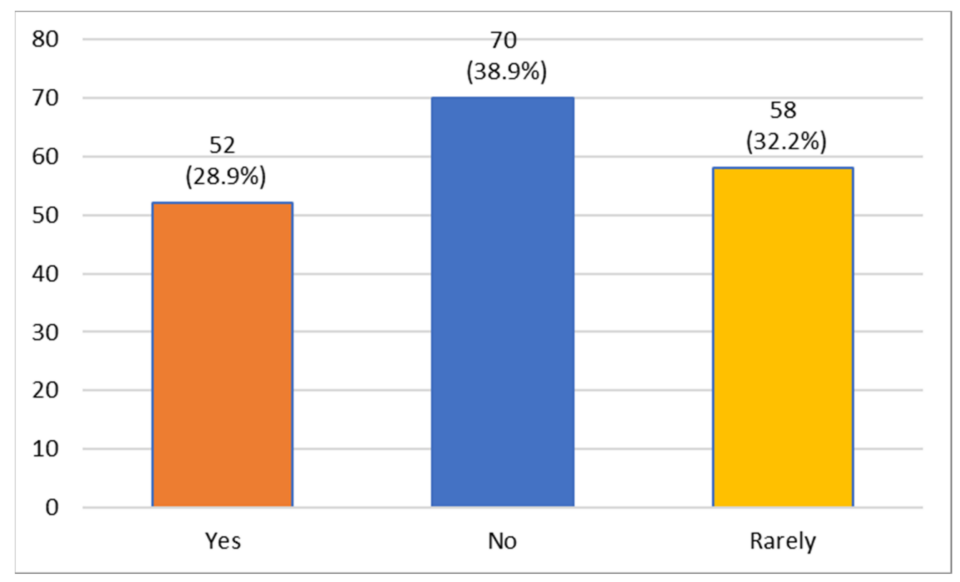

Figure 5. Distribution of the answers given by children regarding organic products.

An increased number of children $(75.6 \%, n=136)$ have breakfast while only a few have breakfast occasionally $(13.9 \%, n=25)$ or none $(10.6 \%, n=19)$ (Figure 6).

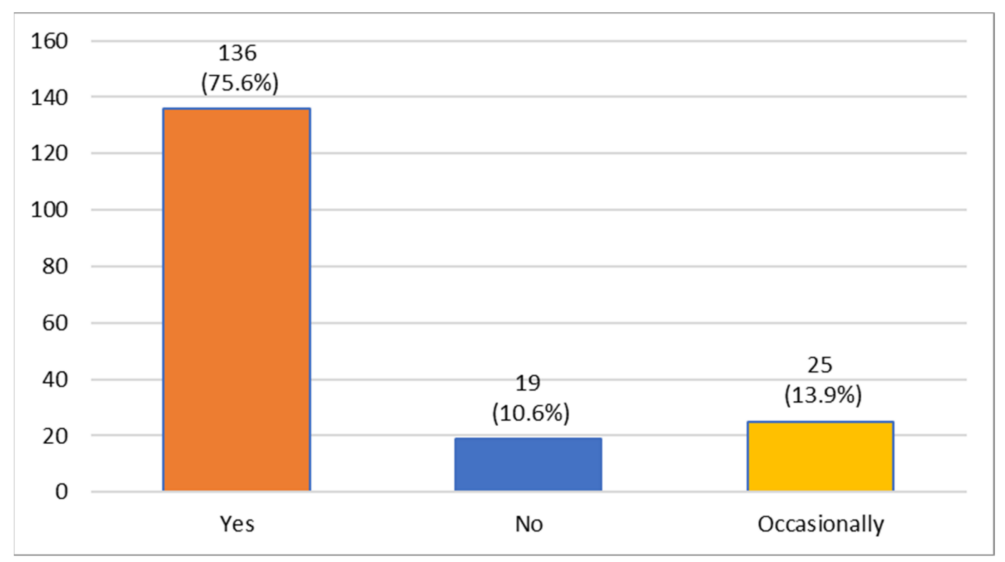

Figure 6. Distribution of the answers given by children regarding breakfast products.

Additionally, a high number of children $(69.5 \%, n=123)$ have a morning snack prepared from home, while only a few take snacks from canteens $(15.3 \%, n=27)$ or food kiosks $(11.9 \%, n=21)$ (Figure 7 ).

The dietetic habits and attitude of adults are reported in Figures 8-13. The majority of adults $(61.2 \%, n=237)$ adopt a healthier nutrition (low fat, low sugar, more vegetables) while only a few are not interested $(6.2 \%, n=24)$ or have constraints to adopting it $(32.6 \%$, $n=126$ ) (Figure 8).

A high number of adults $(96.1 \%, n=370)$ are not interested in a vegetarian diet while only a few are interested $(3.9 \%, n=15)$ (Figure 9). 


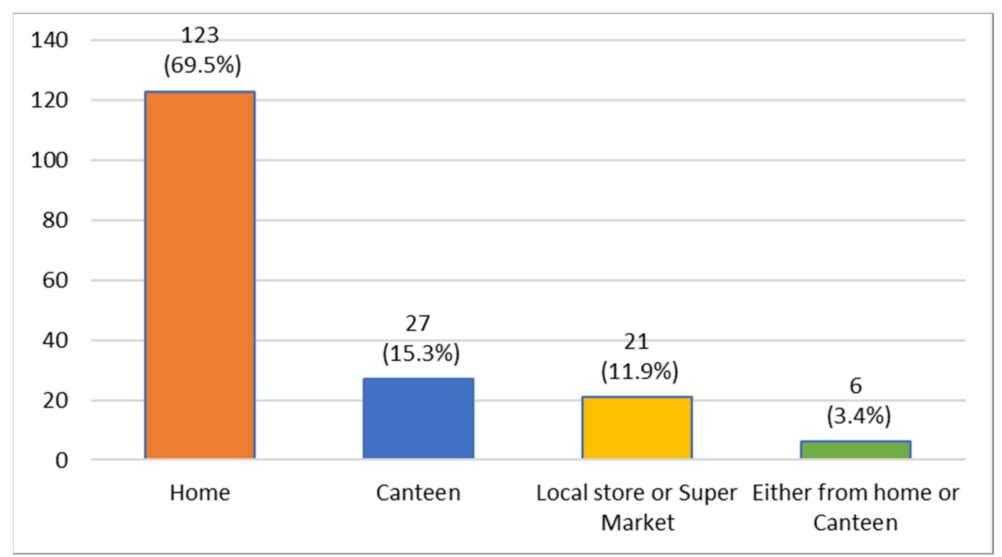

Figure 7. Distribution of the answers given by children regarding morning snacks.

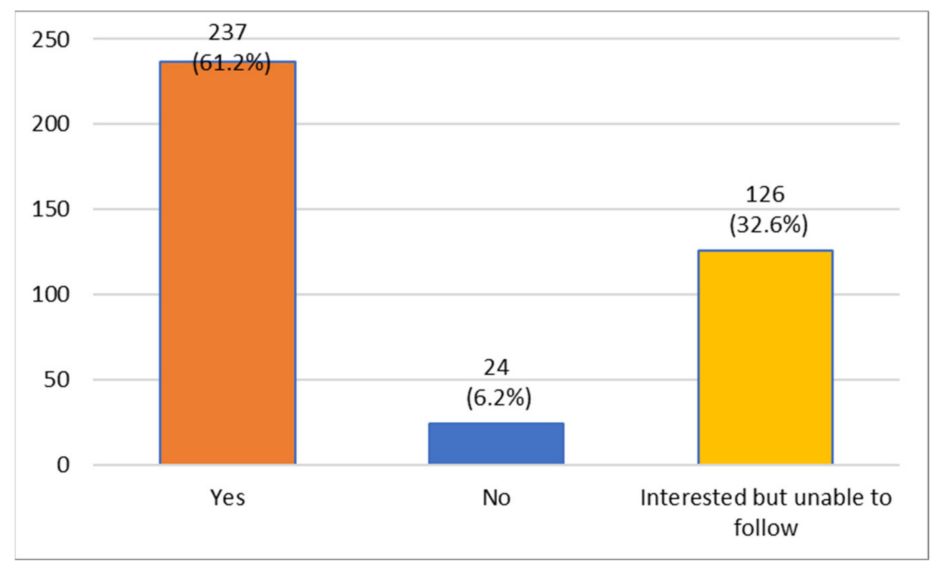

Figure 8. Distribution of the answers given by children regarding healthy nutrition.

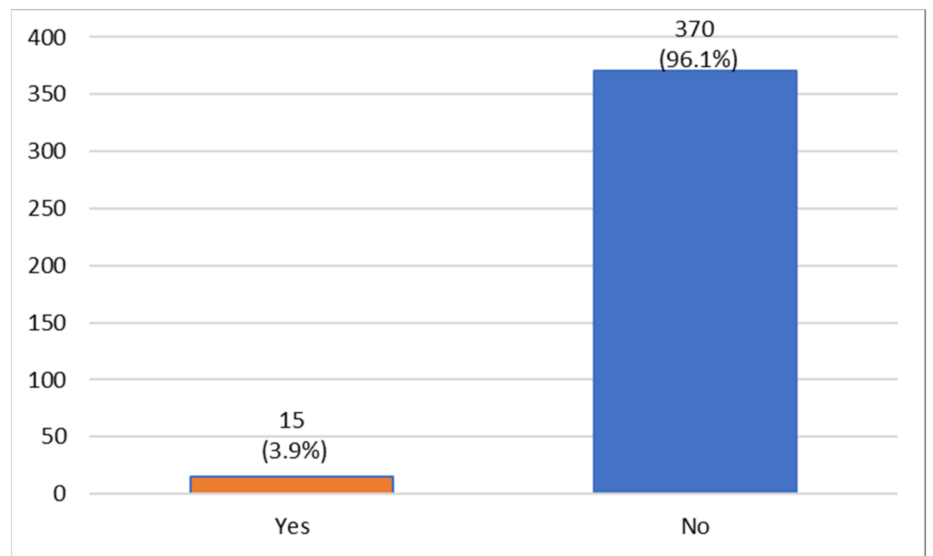

Figure 9. Distribution of adult according to the adoption or not exclusively vegetarian diet in Evros.

In Figure 10, a high number of adults $(70.1 \%, n=272)$ have breakfast while only a few do have $(13.9 \%, n=54)$ or rarely have breakfast $(16 \%, n=62)$. 


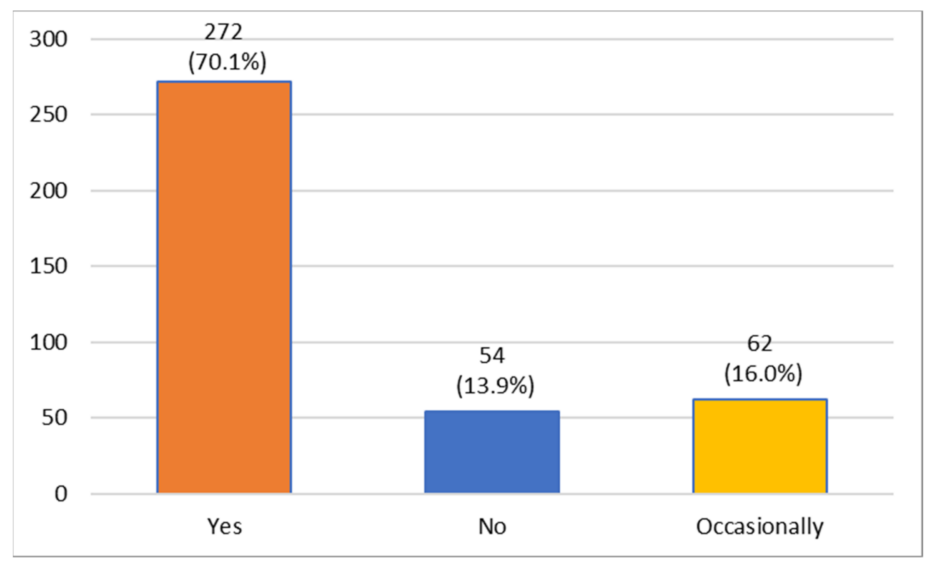

Figure 10. Distribution of adults following breakfast intake in Evros.

A considerable number of adults $(46 \%, n=178)$ have three meals per day, while only a few have one $(2.6 \%, n=10)$ or two $(20.4 \%, n=79)$ or more $(31 \%, n=120)$ (Figure 11$)$.

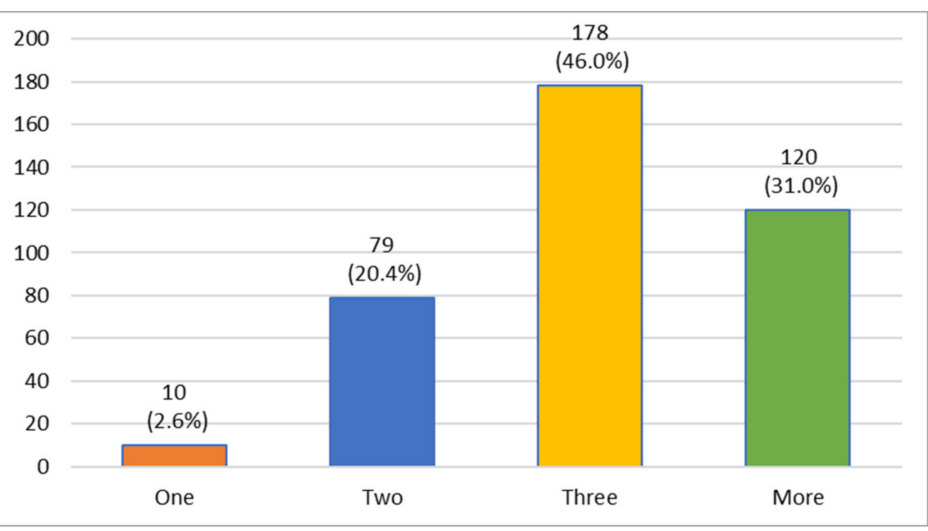

Figure 11. Distribution of the answers given by children regarding number of meals.

The majority of adults choose their food based on their preferences $(75.3 \%, n=287)$, while $9.4 \%(n=36)$ follow their health issues or choose in order to prevent a possible health issue $(11.3 \%, n=43)$ (Figure 12).

Most adults rarely consume organic food products $(45.1 \%, n=173)$ while only a few select them $(30.2 \%, n=116)$ and $24.7 \%(n=95)$ never choose to buy such foods (Figure 13).

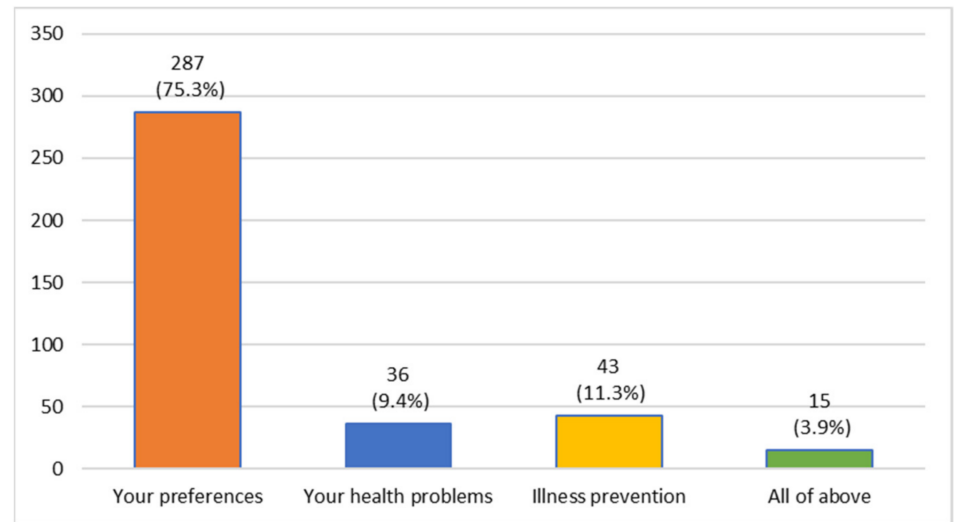

Figure 12. Distribution of the answers given by children regarding food preference. 


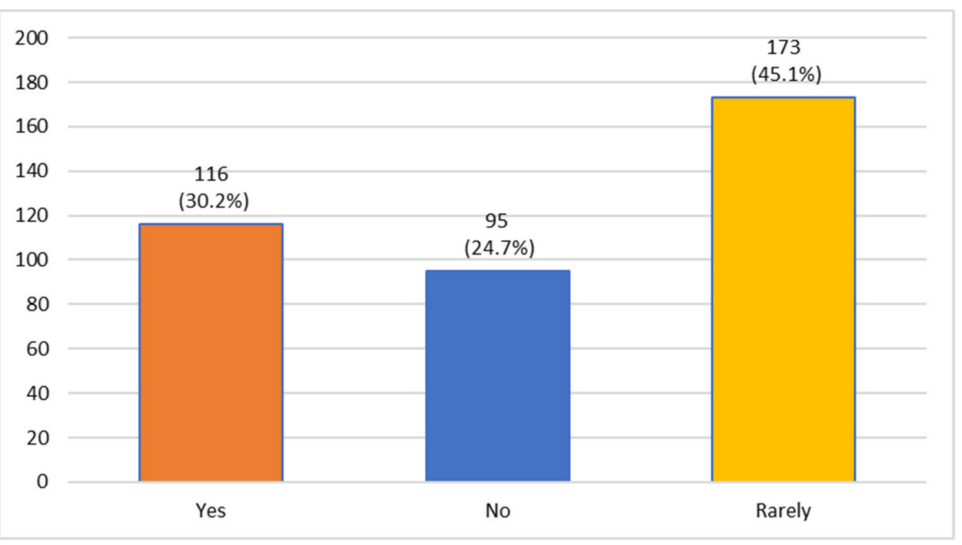

Figure 13. Distribution of children according to their interest in the consumption of biological products in Evros.

\section{Discussion}

As stated previously, the concept of OHRQOL is of an angular stone to shape oral health [35], dental practice and education [30]. The most popular approach is the one based on questionnaires as is the case of our research. The target group in our study was a randomly selected population of minors and adults from an area in NE-Greece.

\subsection{Children Group}

In our survey, from a total of 186 Greek children aged 1-17 years (99 boys and 87 girls) $91.8 \%$ showed excellent health, while only $1.5 \%$ received medication. Regarding the oral health in children, we observed that $18.8 \%$ of the target group had no disease, while $6.1 \%$ developed caries, $5.5 \%$ periodontitis and $1.1 \%$ gingivitis. Our results differ from those of another Greek study [40], where children aged 5 years had caries at a rate of $29 \%$, children aged 12 years at a rate of $68 \%$ and children aged 15 years at a rate of $78 \%$.

Sociodemographic parameters, residence area and parents' education seem to maintain a capital role in the development of healthy eating habits, oral hygiene and prevalence of caries in children [40,41]. In a survey in 2004, gingivitis was observed in 5-year-old children $(15.7 \%), 12$-year-old children (41.5\%) and 15-year-old children (30\%) [40]. However, in 2013, an increase was observed in the 5-year-old children (28.6\%), while a decrease was stated for the 12-year-old children (22.2\%) and 15-year-old children (21\%) [40]. Observed differences could be attributed to the fact that our research concerns only urban areas, where there is greater access to dental services and more information on oral health and oral hygiene. Our target children group had successfully implemented sealing (35.8\%), teeth extractions $(9.5 \%)$, denervation $(4.7 \%)$ and cleaning cure $(20.4 \%)$.

Prevalence of caries (50.3\%) was reported under mixed dentition of twelve-year-old children [41], while a decrease was observed under permanent dentition (44.5\%) as well as gingivitis at an increased rate (77\%) [42] in 12-years-old children in north-western rural Kenya. Improper irregular oral hygiene and services due to the remote area and distance from medical services is stated together with missing education in oral health [42].

Research showed the high rate of dental caries in 6-year-old girls $(68 \%)$ and boys $(60 \%)$ but it was slightly lower in 12-year-old girls (63.6\%) and boys (57.9\%) due probably to oral health education and successful dental services.

Children involved in our study received fluoridation therapies (21.9\%) and preventive coverings of holes and slits (7.7\%). In addition, the educational level of the parents (50.5\%) and the high $(3.3 \%)$ or median family income $(72 \%)$ were evaluated. Most children were informed on oral hygiene rules either by their doctors $(70.4 \%)$, schools $(13.3 \%)$, the internet $(3.4 \%)$ or other $(2.5 \%)$. Only $4.4 \%$ of children had absolutely no information.

Regarding the adoption of oral hygiene rules, children brushed their teeth 2-3 times a day $(23 \%)$, once a day $(55.2 \%), 1-3$ times a week $(12.6 \%)$ and never $3.3 \%$. There is evidence 
that the female population show more interest in oral hygiene than the male population without fully applying all oral hygienic rules.

Another study which enrolled a rural child population showed that children who rarely brush their teeth $(7.7 \%)$ have a similar rate to that in our study, but children that of who never brush is higher (12.6\%) compared to our results [43]. High caries prevalence was associated with manganese and low iron concentrations in drinking water [43], independently of social and demographic status.

Slightly higher than ours results, 10-years old children were shown to brush their teeth $(58.64 \%)$ twice a day [44], while these rates were lower in 12-year-old children (31\%) and 15-year-old children (40.4\%) in another study [45].

Preschool children of Sri Lanka recorded increased rates of brushing frequency as $80 \%$ brush their teeth twice a day, $15 \%$ once and $5 \%$ more than twice [46]. Despite this fact and the use of toothpaste with fluoride at a rate of $84 \%$, caries' prevalence appears high $(65 \%$ in 5 -year-old children). This has been attributed to poor eating habits and the absence of oral health promotion programs.

In our study children use fluoride toothpaste $(69.8 \%)$ which provides protection against tooth decay by promoting the demineralization of the damaged enamel as well as inhibiting bacterial metabolism of sugars. However, additional oral hygiene measures such as dental solution (boys $28.7 \%$ and girls $32.9 \%$ ) were limited. Studies [44] reported children using dental floss in much higher rates than our study $(36.84 \%)$, while research has shown the complete absence of fluoride products on a daily basis [45].

Focusing on the dietetic habits, we perceive that the participating children $(14.3 \%$ girls and $7.3 \%$ boys) skip breakfast, although this meal is considered the most important meal of the day, as it supplies the body with energy and nutrients to maintain our functions and activities. The famous words of the nutritionist and author Adelle Davis (1904-1974) are well-known: "Eat breakfast like a king, lunch like a prince and dinner like a poor man". Breakfast intake is still associated with increased brain activity, school performance, attention, memory and mental health. The proportion of children in our survey who occasionally have breakfast ( $15.6 \%$ of boys and $11.9 \%$ of girls) is lower compared to those receiving regularly their breakfast meal ( $77.1 \%$ of boys and $73.8 \%$ of girls). Similarly, $81 \%$ of Brazilian children regularly have breakfast, $12 \%$ occasionally and only $7 \%$ do not receive any breakfast [47]. However, in this study, no difference was found in terms of gender or weight of children in contrast to our study, where girls skip breakfast more often than boys, probably due to improper habits for losing weight. Swedish adolescents are reported to skip breakfast at higher rates than in our country ( $20 \%$ of boys and $32 \%$ of girls) [48], while, similarly, in Switzerland ( $27 \%$ of boys and $24 \%$ of girls) young children skip breakfast [49]. Urban adolescents skip breakfast more frequently than children living in rural areas, as well as adolescents coming from families with low socioeconomic status.

Almost half of the studied children in our survey ( $53 \%$ boys and $46.8 \%$ girls) have a morning snack. The most common snacks are toast (34.6\%) and fruit $(21.4 \%)$, followed by cheese pie ( $8.8 \%$ ) and, to a lesser extent, other types of products (cakes, buns, juice, pizza, sweets, etc.). It is encouraging that our children have adopted healthier choices as they have healthy snacks mostly prepared from home (73\% of boys and $66.3 \%$ of girls) and less from the canteen (16.8\% of boys). In contrast, morning snacks in the Scandinavian countries are common however unhealthy (soft drinks, cakes, buns, chips and ice cream) [50]. Another Greek survey [51] states that $85 \%$ of preschool children have a snack daily, $14 \%$ rarely and $1 \%$ never. Their results are in accordance with our study, as the snack is home-prepared $(78 \%)$, while only few children ( $12 \%)$ have their snack from the canteen. As for the nature of the snack, they have mainly milk (37\%), fruit $(29 \%)$, juice $(28 \%)$, toast $(25 \%)$ and to a lesser extent other foods such as toast (55\%), egg (51\%), bread with honey $(50 \%)$, a bun $(48 \%)$, pie or fruit $(43 \%)$ on a daily basis. Besides the differences in dietary preferences of children from those involved in our study, we must accept the healthy quality of their snacks.

Children involved in our study consume on dairy products a daily basis $(73.1 \%)$, followed by fruits $(47.3 \%)$, vegetables (35.2\%) and sugary foods $(32.8 \%)$. At lower rates, 
children consume nuts $(14.9 \%)$, soft drinks $(7.2 \%)$, meat (5.5\%), fast food $(2.2 \%)$ or fish $(0.6 \%)$ daily. Meat is consumed in most cases $2-3$ times a week $(66.5 \%)$, fish once a week $(50.8 \%)$, vegetables $2-3$ times a week $(39.6 \%)$, fast food products once a week $(34.8 \%)$, nuts once a week (26\%), sweets $2-3$ times a week (38.3\%) and finally soft drinks once a month $(21.5 \%)$. Without any doubt, the high consumption of dairy products on a daily basis is encouraging which, due to their ingredients (calcium, phosphorus, casein, fats), protect against caries by inhibiting the attachment of Streptococcus mutans to dental surfaces, and also inhibit bone loss in periodontal disease.

Swiss teenagers seem to consume dairy products daily $(80 \%)$, which is not far from our results. The same adolescents consume a very low percentage of fish every day ( $2 \%$ for girls and 3\% for boys), however this is slightly higher than the proportion of children in our survey $(0.6 \%)$. Consumption of vegetables is higher in dietetic habits of children in Switzerland (76\% of girls and 59\% of boys) compared to children in our study (35.2\%). The same applies to the daily consumption of fruit ( $70 \%$ of girls and $45 \%$ of boys) compared to the children in our study (47.3\%). Our results are almost in line with a Swedish study [50], in which fruits and vegetables make up $40 \%$ of the daily intake of 15 -year-olds. In part, our findings are in agreement with those of another Greek team [52]. The study was undertaken on a national level and adolescents at least $40 \%$ were shown to consume of vegetables daily and $75 \%$ fruits, following the standards of the Mediterranean diet [52].

In the countries of Southern Europe, fast food products are consumed no more than once a week, while in the USA $20 \%$ of children consume such foods almost every day in restaurants. In our research only $2.2 \%$ of children consume fast food, however this is slightly higher compared to another study in our country (1\%) [51]. According to this latter study, Greek children consume fast food 3-4 times a week (5\%), 1-2 times a week (63\%) and not at all (33\%). In our research, children who do not consume such foods at all are found in a lower amount $(16 \%)$, while they consume them $2-3$ times a week $(18.2 \%)$, once a week $(34.8 \%)$ and once month $(28.7 \%)$ as shown. Eating fast food has been implicated in the development of caries, but also many other health problems such as obesity, hypertension and cardiovascular disease. Undoubtedly, children are exposed to high intakes of sugars, fats and sodium.

Concerning sugary foods, in our study children consume lower sugar (32.8\%) when compared with other Greek studies (53.2\%) [43]. Moreover, $6.1 \%$ of the children in our survey do not consume any sugary food which is also lower compared to the mentioned study (10\%). In accordance with our study, in Spain [53] children that never consume sugar are few $(6.1 \%)$, while they do so during gathering with friends $(73.8 \%)$ and on other occasions (17.8\%). According to a Nestle Research Center study [54], the daily intake of sugary foods is close to our findings (27\% of girls and $27 \%$ of boys). However, Swiss adolescents rarely consuming sugar foods ( $15 \%$ of girls and $10 \%$ of boys) are found in higher rates than in our study.

The consumption of sugary foods in our sample seems to be irrelevant to the main meal (66.3\%), while children consume such foods after the meal (32.6\%). This is detrimental, as proven studies have shown that sugary foods cause more caries when eaten between meals than immediately after a main meal. The amount and frequency of consumption of sugary foods play an important role in the development of caries. It is noteworthy that caries have a cumulative character with age and the effect of sugars on dental tissues is lifelong. Childhood is crucial for determining caries levels throughout a person's life. In Romania [54], children seem to usually have meals with moderate carbohydrate intake $(43.71 \%)$ more often than meals with high carbohydrate intake $(30.31 \%)$. In fact, only $13.32 \%$ of the children consume carbohydrates more than seven times a day. It is stated that replacement of sucrose in foods and beverages by substitutes such as xylitol and other polyols which are reported to not cause carries could be a good dietary strategy. Without any doubt, it is crucial to raise the awareness of children, but also of parents on issues of healthy eating and oral hygiene. 
In terms of eating habits, children outside Evros consume products rich in sugar 2-3 times a week or even daily, more frequent compared to the children in Evros. However, sugary foods consumption is not done during their meal. This explains the appearance of caries to a greater extent in children outside Evros. Sugar substitutes are not among the preferences of children both in Evros and outside Evros and they are consumed rarely inside Evros or outside Evros.

Children outside Evros have dairy products and fruits-vegetables included daily or 2-3 times a week in their diet compared to that of Evros. Fish is usually eaten once a week or less, while meat is consumed much more frequently. Children outside Evros living in bigger towns are always "ahead", coupling healthy habits with unhealthy ones! Fast food products are consumed more frequently by children outside Evros, while children prefer healthy choices that refer to the model of the traditional Mediterranean diet; as a result of their education, they turn in parallel to Western eating habits promoted by advertisements and Western culture.

\subsection{Adult Group}

In our survey, from a total of a stratified cluster sample of 390 adults (148 men and 242 women) aged from 18 to more than 50 years old, 62.4\% of them show excellent, $35 \%$ moderate, while only $2.6 \%$ serious health status. The most common diseases are diabetes, hypertension and thyroid disease and only $39.4 \%$ receive medication for different disease states. Regarding oral health in adults, we observed that $18.6 \%$ of our target group had no disease, while $3.2 \%$ developed caries, $4 \%$ gingivitis and a lower percentage of $1.3 \%$ periodontitis or orthodontic abnormalities (1.6\%). It is of note that the extracted teeth rate not replaced by prosthetic work $(9.5 \%)$ was found to be considerable.

Nevertheless, in divergence with our study, research in adults aged 35-44 years and 65-74 years shows caries (99.3\% and 99.9\%, respectively) [40], while periodontitis and edentulism increase with aging, as shown similarly in our study.

High rates of caries are highlighted in Kosovan adults (72.80\%) [55]. More specifically, the caries prevalence rates are $44.2 \%$ for adults $18-34$ years old, $18.3 \%$ for $35-44$ years old, $17.2 \%$ for $45-64$ years old, $17.3 \%$ for $65-74$ years old and finally $2.9 \%$ for 75 years old.

Prevailing caries rates observed in a Jordanian population reach $24 \%$, which is comparable to our results [56], while $85 \%$ show one or more missing teeth, a significantly higher percentage than that observed in our research.

The rate of periodontitis in adults and the elderly in Germany seems to be higher than our study [57]. Those adults suffer from moderate periodontitis at a rate of $52.7 \%$ and severe periodontitis at a rate of $20.5 \%$, while the corresponding rates for the elderly are $48 \%$ and $39.8 \%$, respectively. Yet, the average number of missing teeth is $2.7 \%$ for adults and $14.2 \%$ for the elderly.

The oral health status in our adult target group appears to be better compared to other surveys either in our country or in other countries. As we have already pointed out, our research concerns only urban areas, where there is greater access to dental services and more information on oral health and oral hygiene. On one hand, 50.4\% of the target adult group does not present any dental problem but, on the other hand, the interest of adults for dental therapy is remarkable, since $38.8 \%$ of occlusions, $12.3 \%$ of denervations, $14 \%$ of extractions and $20.4 \%$ of cleanings had been implemented. In addition, patients had undergone fixed prosthetic restorations with a predominance of bridges (50.3\%) or crowns (23\%) or implants $(15.8 \%)$, while the percentage of removable dentures is lower (partial dentures at a rate of $7.3 \%$ and total dentures at a rate of 3.6\%). Similarly, in most European countries half of the adult population wear any type of denture (removable or fixed). The percentage of adults who have removable dentures ranges from $13-29 \%$ with $3-13 \%$ of them having full dentures in both jaws, while the percentage who have fixed dentures ranges from 34\% (Switzerland) to $45 \%$ (Sweden) [58]. In an adult study in France [58], it was found that fixed dental works (crowns, bridges) were required at a slightly higher rate $(51.9 \%)$. Undoubtedly, in recent decades there has been an interest in 
preserving natural teeth as much as possible, resulting in reduced tooth decay, reduced use of complete dentures and a higher frequency of fixed prosthetic work.

In addition, the educational level of the adults' target group was evaluated as high $(40.6 \%)$, upper $(25.1 \%)$ and average $(23.7 \%)$ as well as the median family income $(78.1 \%)$. These factors contribute positively to the improved picture of the oral health of adults included in our study. Yet, most adults were informed on oral hygiene rules either by their doctors $(64.3 \%)$ or to a lesser extent by scientific speeches, the press, the internet and other sources. Lastly, only $5.7 \%$ of our adult target group had absolutely no information.

Regarding the adoption of oral hygiene rules [59], in our research adults brush their teeth $2-3$ times a day ( $41.4 \%$; women $46.7 \%$ vs. men $32.6 \%)$, once a day $(50.3 \%$; men $56.3 \%$ vs. women $46.7 \%)$ and $1-3$ times a week $(5.5 \%)$, rarely $(2.1 \%)$ or never $(0.8 \%)$. Women seem to be more interested in oral hygiene practices than men; however, despite adequate information, the sample does not fully apply the rules of oral hygiene. Research on young adults in Turkey [60] showed that they brush their teeth at a similar frequency to us of twice a day $(44.2 \%)$, while a lower rate is reported for young adults brushing their teeth $(30.8 \%)$ once a day. Women seem to care for their oral hygiene more frequently than men. The same conclusion was reached in a Polish study [61]; adults brush their teeth once a day $(77 \%)$ which is much higher than our study group or never (20\%). In Germany [57], a considerable sample of adults usually brush their teeth twice a day $(72.8 \%)$ followed by the elderly (60.6\%).

In our study, adult used fluoride toothpaste (78.6\%); this provides protection against tooth decay. Notwithstanding, supplementary oral hygiene measures $(47.2 \%)$ were limited. However, a study in Turkey [62] reported that adults never use additional oral practices such as dental floss ( $81 \%)$ or mouthwash $(3 \%)$.

Regarding the frequency of visits to the dentist in our research, only $48.2 \%$ of the target adult group visit the dentist mainly when there is a serious oro-dental problem or pain and it was rarer for preventive reasons $(25.3 \%)$. As in the case of children, this attitude indicates negligence or dentist fear and lack of awareness of the value of prevention or even inability to cover the cost of dental treatment due to the financial crisis. Our results are in line with those of another Greek study [40], which report that adults visit the dentist upon pain $(47.4 \%)$, while few adults come to the dentist for preventive reasons $(22.7 \%)$.

Another study stated [60] that Turkish adults visit the dentist when there is a problem $(82.9 \%)$ and much less for preventive reasons (11.3\%) every semester or every year (5.8\%). In contrast, Polish adults [61] are more consistent in their visits to the dentist as they regularly visit their dentists every year (72\%), every 6-11 months (17\%) and rarely every six months (5\%). However, both adults and the elderly in a German survey [55] appear to be in compliance with the schedule of visits to the dentist once a year at a rate of $76.1 \%$ and $72.2 \%$, respectively.

Regarding the dietary habits of our adults' group, most of them have breakfast daily $(70.1 \%)$ or sometimes $(16 \%)$, while $13.9 \%$ skip it. Similarly, most adults in the United States [63] seem to have breakfast daily $(80.3 \%)$ and only few of them skip it (19.7\%). UK adults showed a slightly different image [64]. Despite the assumption that English people consume "big fatty" breakfast, it is reported that only $64 \%$ have a breakfast daily, while $30 \%$ occasionally have breakfast and $6 \%$ never. As is known, skipping breakfast has been linked to poor nutrition, poor cognitive function [63] and health problems such as type 2 diabetes [65], obesity [66] and cardiovascular disease [67].

In our research, adults prefer to consume vegetables $(52.9 \%)$, dairy $(51.6 \%)$, fruits $(48.4 \%)$, sugary foods $(27.6 \%)$ and to a lesser extent other food on a daily basis. Besides sugary foods, foods included in their daily diet are considered healthy choices rich in nutrients with positive benefits for both oral health and overall health. In particular, their diet is based on meat $(66.3 \%)$, nuts $(29.1 \%)$ and foods rich in sugar $(33.9 \%)$ which are consumed 2-3 times a week, while fish (62.8\%) is consumed one time per week and less frequently fast-food products (35.1\%) with soft drinks (20.9\%) once a month. 
Similarly, adults in Kenya consume daily vegetables (50.9\%) but the daily consumption of fruits is quite low (15.3\%) [68]. Adults in Ethiopia equally consume low amounts of fruits [69]. Lower fruits consumption is also stated for adults in Thailand (36.5\%) in contrast to the percentage consumed of vegetables $(68 \%)$, which is higher [70]. In an attempt to understand this attitude, as those countries are fruits-producers, we believe that low consumption of fruits in Africa and Asia must be explained by the high cost for local residents due to their low income and also to the need for "stuffy" feed for nutrition. Moreover, it seems to be correlated with sociodemographic factors and lack of education [69].

In contrast, older adults in Brazil seem to consume fruits and vegetables more than four times a week (south; $77.6 \%$, north-east; $71.5 \%$ ), as well as to consume dairy products every day (south; $86.3 \%$, northeast; $65.7 \%$ ) [71]. However, meat or fish consumption is listed as high—at least three times a week (98.7\% and 90.7\%, respectively) [71].

Finally, the consumption of sugary foods in our target group is independent to the main meal $(68.3 \%)$, while adults equally consumed sugary foods after the meal $(30.6 \%)$ or did not $(1.1 \%)$. As we have already pointed out, the consumption of food regardless of the meal is detrimental for oral health. However, the development of caries is closely associated to the quantity and frequency of the intake of sugary foods. In this vein, the low rate of caries in adults can be justified (a) by the use of fluoride toothpaste, which consists of an effective measure for the prevention and control of caries and (b) by more frequent visits to the dentist $(25.9 \%)$, during the last semester $(31.4 \%)$ or the last year $(22.8 \%)$. It is of note that the use of sucrose substitutes would be a good choice against caries, but only few people have acquired this habit in general $(11.2 \%)$. It is then conceivable that more awareness of adults on issues of healthy eating and oral hygiene must be raised.

In terms of eating habits, adults outside Evros consume products rich in sugar more frequently compared to adults in Evros. Consumption does not occur during the main meal. This explains the appearance of caries to a greater extent in adults outside Evros. Sugar substitutes are not the favorite among the preferences of adults both in Evros and outside Evros.

Adults outside Evros consume dairy products on a daily basis compared to the adults of Evros. Similarly, fruits and vegetables are consumed more frequently by non Evros residents. Fish is consumed more rarely in both groups. Fast food products are consumed mainly once a month from adults outside Evros. Adults prefer healthy options in line with the traditional Mediterranean diet and are less likely to turn to Western-style eating habits like children.

\section{Conclusions}

Bacteria species typically associated with the oral microbiota have been found to be present in oral disease, which is a major public health challenge worldwide today. The most common oral diseases are caries and periodontal disease. At the end of the second decade of the 21st century, a decrease in the prevalence of caries and periodontal diseases was observed in Greek children and adults' nutrition which seems to be in line with the standard of the Mediterranean diet which facilitates healthy choices (dairy, fruits, vegetables) on a daily basis. Foods rich in sugar are consumed exceptionally on a daily basis by few individuals. Sucrose substitutes are not used by a large sample of the population. Yet, Greek preferences are not focused on vegetarian diets or organic foods. Foods are purchased from local markets mostly in rural areas while in towns people use supermarkets.

The educational level of our sample was mostly higher or median education, while the family income was average. Both factors contribute to the improved clinical image of oral health. Regarding the adoption of oral hygiene rules, both adults and children brush their teeth daily and a small proportion 2-3 times a day. However, additional oral hygiene measures are taken by few individuals. Women are more interested in oral hygiene than men. 
It is encouraging that fluoride toothpaste is used, which protects against caries. Nevertheless, preventive dental treatments such as fluoridation, preventive occlusion and sealing are rare and visits to the dentist are made when a problem or pain appears.

Evros people show less interest in preventive and other dental therapies. In terms of eating habits, children and adults outside Evros are more interested in healthy eating than children and adults in Evros, although they often consume sugary foods and often outside of their main meal. The partial shifting to the standard of the Mediterranean diet and less to the standard of Western type foods is of note.

In this light, in order to promote oral health and prevent disease, it is a requisite to raise the awareness of both children and adults, especially in the remote area of Evros, through informational campaigns and educational programs on oral health, oral hygiene and the benefits of a balanced diet.

Limitations: Caries prevalence was calculated based on the percentage of positive cases and no DMFT (Decay, Missing, Filled, Teeth) and SiC (Signifi-111 cant Caries Index) clinical caries index were calculated as physical clinical examination was not performed.

Author Contributions: Conceptualization, E.B. and A.M.; methodology, E.B. and A.M.; formal analysis, A.A. resources, E.B., A.M., I.M., S.P., C.V. and C.T.; data curation A.A.; writing-original draft preparation, E.B. and A.M.; writing-review and editing, E.B., I.M., S.P., C.V. and C.T.; visualization, E.B., C.T. and A.M.; supervision, E.B.; project administration, E.B.; funding acquisition, E.B. All authors have read and agreed to the published version of the manuscript.

Funding: This research received no external funding.

Institutional Review Board Statement: Since this study completed was before 2018 no approval from the EHDE was required, although all measures were taken to insure the privacy of respondents (minors and adults). During the survey no data leading to the identification of any person were collected, no physical examination occurred, and minors always accompanied by their guardians.

Informed Consent Statement: The informed consent was obtained from all subjects by filling in the questionnaire.

Data Availability Statement: Questionnaire and Data are available upon reasonable request.

Conflicts of Interest: The authors declare no conflict of interest.

\section{References}

1. Stavropoulou, E.; Kantartzi, K.; Tsigalou, C.; Konstantinidis, T.; Voidarou, C.; Konstantinidis, T.; Bezirtzoglou, E. Unraveling the interconnection patterns across lung microbiome, respiratory diseases and COVID-19. Front. Cell. Infect. Microbiol. $2021,10,892$. [CrossRef] [PubMed]

2. McLean, J.S. Advancements toward a systems level understanding of the human oral microbiome. Front. Cell. Infect. Microbiol. 2014, 4, 98. [CrossRef] [PubMed]

3. Fadel, H.T.; Zolaly, M.A.; Alharbi, M.O.; Qarah, L.A.; Alrehili, M.S.; Alamri, A.D.; Tarawah, A.M. Oral health profiles and related quality of life in thalassemia children in relation to iron overload: A cross-sectional study. Int. J. Environ. Res. Public Health 2020, 17, 9444. [CrossRef]

4. Zaborskis, A.; Kavaliauskienè, A.; Šidlauskas, A. Family affluence based inequality in oral health-related quality of life in a population of Lithuanian adolescents. Int. J. Environ. Res. Public Health 2019, 16, 2106. [CrossRef]

5. Saito, S.; Aoki, Y.; Tamahara, T.; Goto, M.; Matsui, H.; Kawashima, J.; Danjoh, I.; Hozawa, A.; Kuriyama, S.; Suzuki, Y.; et al. Oral microbiome analysis in prospective genome cohort studies of the Tohoku medical megabank project. Front. Cell. Infect. Microbiol. 2020, 10, 873. [CrossRef]

6. Lattanzi, A.P.D.S.; Silveira, F.M.; Guimaraes, L.; Antunes, L.A.A.; Antunes, L.D.S.; Assaf, A.V. Effects of oral health promotion programmes on adolescents' oral health-related quality of life: A systematic review. Int. J. Dent. Hyg. 2020, 18, 228-237. [CrossRef]

7. Petersen, P.E.; Bourgeois, D.; Ogawa, H.; Estupinan-Day, S.; Ndiaye, C. The global burden of oral diseases and risks to oral health Bull. World Health Organ. 2005, 83, 661-669.

8. Watanabe, M.; Nakatani, E.; Yoshikawa, H.; Kanno, T.; Nariai, Y.; Yoshino, A.; Vieth, M.; Kinoshita, Y.; Sekine, J. Oral soft tissue disorders are associated with gastroesophageal reflux disease: Retrospective study. BMC Gastroenterol. 2017, 17, 1-10. [CrossRef]

9. Yadav, K.; Prakash, S. Dental caries: A review. Asian J. Biomed. Pharm. Sci. 2016, 6, 1-7. [CrossRef]

10. National Institute of Health (NIH). Periodontal (Gum) Disease: Causes, Symptoms, and Treatments; NIH Publication: Bethesda, MD, USA, 2016. 
11. Sonkusale, K.D.; Tale, V.S. Isolation and characterization of biofilm forming bacteria from oral microflora. Int. J. Curr. Microbol. Appl. Sci. 2015, 2, 118-127.

12. Borojevic, T. Smoking and periodontal disease. Mater. Socio Med. 2012, 24, 274-276. [CrossRef]

13. Pflipsen, M.; Zenchenko, Y. Nutrition for oral health and oral manifestations of poor nutrition and unhealthy habits. Gen. Dent. 2017, 65, 36-43.

14. Stookey, G.K. The effect of saliva on dental caries. J. Am. Dent. Assoc. 2008, 139, 11S-17S. [CrossRef]

15. Treister, N.; Glick, M. Rheumatoid arthritis: A review and dental care considerations. J. Am. Dent. Assoc. 1999, 130,689-698. [CrossRef]

16. Akazawa, H. Periodontitis and diabetes mellitus: Be true to your teeth. Int. Heart J. 2018, 59, 680-682. [CrossRef]

17. Harris, R.; Nicoll, A.D.; Adair, P.M.; Pine, C.M. Risk factors for dental caries in young children: A systematic review of the literature. Community Dent. Health 2004, 21, 71-85.

18. Khan, S.; Barrington, G.; Bettiol, S.; Barnett, T.; Crocombe, L. Is overweight/obesity a risk factor for periodontitis in young adults and adolescents?: A systematic review. Obes. Rev. 2018, 19, 852-883. [CrossRef]

19. Petersen, P.E.; Ogawa, H. The global burden of periodontal disease: Towards integration with chronic disease prevention and control. Periodontol. 2000 2012, 60, 15-39. [CrossRef]

20. Müller, F.; Shimazaki, Y.; Kahabuka, F.; Schimmel, M. Oral health for an ageing population: The importance of a natural dentition in older adults. Int. Dent. J. 2017, 67, 7-13. [CrossRef]

21. Ehizele, A.; Ojehanon, P.; Akhionbare, O. Nutrition and oral health. Benin J. Postgrad. Med. 2009, 11. [CrossRef]

22. WHO. Malnutrition. Available online: https://www.who.int/news-room/q-a-detail/malnutrition (accessed on 20 December 2020).

23. Nilsson, H.; Sanmartin Berglund, J.; Renvert, S. Longitudinal evaluation of periodontitis and tooth loss among older adult. J. Clin. Periondontol. 2019, 46, 1041-1049. [CrossRef]

24. Murtaza, N.; Burke, L.M.; Vlahovich, N.; Charlesson, B.; O’Neill, H.M.; Ross, M.L.; Campbell, K.L.; Krause, L.; Morrison, M. Analysis of the effects of dietary pattern on the oral microbiome of elite endurance athletes. Nutrients 2019, 11, 614. [CrossRef]

25. Stavropoulou, E.; Tsigalou, C.; Bezirtzoglou, E. Functions of the human intestinal microbiota in relation to functional foods Erciyes Med. J. 2018, 40, 188-193. [CrossRef]

26. Zec, M.; Rajilić-Stojanović, M. Nutrition and microbiota. Microb. Health Dis. 2020, 2, e293. [CrossRef]

27. Mortazavi, S.; Noin, S. Plaque PH changes following consumption of two types of plain and bulky bread. Dent. Res. J. 2011, 8, 80-84.

28. Stephan, R.M.; Miller, B.F. A quantitative method for evaluating physical and chemical agents which modify production of acids in bacterial plaques on human teeth. J. Dent. Res. 1943, 22. [CrossRef]

29. Kleinberg, I.A. Mixed-bacteria ecological approach to understanding the role of the oral bacteria in dental caries causation: An alternative to Streptococcus mutans and the specific-plaque hypothesis. Crit. Rev. Oral Biol. Med. 2002, 13, 108-125. [CrossRef] [PubMed]

30. Bennadi, D.; Reddy, C.V.K. Oral health related quality of life. J. Int. Soc. Prev. Community Dent. 2013, 3, 1-6. [CrossRef]

31. Locker, D. Measuring oral health: A conceptual framework. Community Dent. Health 1988, 5, 3-18.

32. Gift, H.C.; Atchison, K.A. Oral health, health, and health-related quality of life. Med. Care 1995, 33, NS57-NS77. [CrossRef]

33. Baiju, R.; Peter, E.; Varghese, N.O. Oral health and quality of life: Current concepts. J. Clin. Diagn. Res. 2017, 11, ZE21-ZE26. [CrossRef]

34. Al Shamrany, M. Oral health-related quality of life: A broader perspective. East. Mediter. Health J. 2006, 12, 894-901.

35. Listl, S.; Galloway, J.; Mossey, P.; Marcenes, W. Global economic impact of dental diseases. J. Dent. Res. 2015, 94. [CrossRef]

36. Hoyle, J. Study on the cost of untreated dental disease on the Commonwealth. Joint Commision Health Care 2013, 50, 1-21.

37. Dom, T.N.M.; Ayob, R.; Muttalib, K.A.; Aljunid, S.M. National economic burden associated with management of periodontitis in Malaysia. Int. J. Dent. 2016, 2016. [CrossRef]

38. Gill, J.; Johnson, P. Research Methods for Managers, 4th ed.; Sage: London, UK, 2002; ISBN 13978-1847870940.

39. Taherdoost, H. Determining sample size; how to calculate survey sample size. Int. J. Econ. Manag. Syst. 2017, 2, $237-239$.

40. Oulis, C.J.; Tsinidou, K.; Vadiakas, G.; Mamai-Homata, E.; Polychronopoulou, A.; Athanasouli, T. Caries prevalence of 5, 12 and 15-year-old Greek children: A national pathfinder survey. Community Dent. Health 2012, 29, 29-32.

41. Panagidis, D.; Schulte, A.G. Caries prevalence in 12-year-old Cypriot children. Community Dent. Health 2012, $29,297-301$.

42. Owino, R.O.; Masiga, M.A.; Ng'ang'a, P.M.; Macigo, F.G. Dental caries, gingivitis and the treatment needs among 12-year-olds. East. Afr. Med. J. 2010, 87, 25-31. [CrossRef]

43. Tsanidou, E.; Nena, E.; Rossos, A.; Lendengolts, Z.; Nikolaidis, C.; Tselebonis, A.; Constantinidis, T. Caries prevalence and manganese and iron levels of drinking water in school children living in a rural/semi-urban region of north-eastern Greece. Environ. Health Prev. Med. 2015, 20. [CrossRef]

44. Vadiakas, G.; Oulis, C.J.; Tsinidou, K.; Mamai-Homata, E.; Polychronopoulou, A. Oral hygiene and periodontal status of 12 and 15-year-old Greek adolescents. A national pathfinder survey. Eur. Arch. Paediatr. Dent. 2012, 13, 11-20. [CrossRef]

45. Perera, S.N.S.; Abaysena, C. Association of physical activity and consumption of snacks on weight retention at six months after childbirth. J. Coll. Community Physicians Sri Lanka 2020, 26, 104-111. [CrossRef] 
46. Angelopoulou, M.V.; Kavvadia, K.; Oulis, C.; Reppa, C. Oral hygiene facilitators and barriers in Greek 10 years old school-children. Int. J. Clin. Pediatr. Dent. 2015, 8, 87-93. [CrossRef]

47. Pereira, J.L.; de Castro, M.A.; Hopkins, S.; Gugger, C.; Fisberg, R.M.; Fisberg, M. Prevalence of consumption and nutritional content of breakfast meal among adolescents from the Brazilian national dietary survey. Jornal de Pediatria 2018, 94, 630-641. [CrossRef]

48. Post-Skagegård, M.; Samuelson, G.; Karlström, B.; Mohsen, R.; Berglund, L.; Bratteby, L.-E. Changes in food habits in healthy Swedish adolescents during transition from adolescence to adulthood. Eur. J. Clin. Nutr. 2002, 56, 532-538. [CrossRef]

49. Cavadini, C.; Decarli, B.; Grin, J.; Narring, F.; Michaud, P.A. Food habits and sport activity during adolescence: Differences between athletic and non-athletic teenagers in Switzerland. Eur. J. Clin. Nutr. 2000, 54, S16-S20. [CrossRef]

50. Samuelson, G. Dietary habits and nutritional status in adolescents over Europe. An overview of current studies in the Nordicountries. Eur. J. Clin. Nutr. 2000, 54, S21-S28. [CrossRef]

51. Ganiatsa, D. Eating habits of preschool children. University of Ioannina. Dep. Early Child. Educ. 2015. (In Greek) [CrossRef]

52. Yannakoulia, M.; Karayiannis, D.; Terzidou, M.; Kokkevi, A.; Sidossis, L.S. Nutrition-related habits of Greek adolescents. Eur. J. Clin. Nutr. 2004, 58, 580-586. [CrossRef]

53. Smyth, E.; Caamano, F.; Fernández-Riveiro, P. Oral health knowledge, attitudes and practice in 12-year-old school children. Medicina Oral Patologia Oral Cirurgia Bucal 2007, 12, E614-E620.

54. Danila, I.; Hanganu, C.; Barlean, L.; Murariu, A.; Parus, M.; Mihailovici, L.; Saveanu, I.; Timis, T. Trends in oral health status of schoolchildren from Iasi, Romania. J. Oral Health Dent. Manag. Black Sea Ctries. 2004, 3, 45-51.

55. Kamberi, B.; Kocani, F.; Begdati, A.; Kelmendi, J.; Ilijazi, D.; Bersisha, N.; Kqiku, L. Prevalence of dental caries in Kosovar adult population. Int. J. Dent. 2016. [CrossRef] [PubMed]

56. Hamasha, A.A.; Safadi, R.A. Coronal caries experience in dentate Jordanian adults. Community Dent. Health 2008, $25,50-54$.

57. Schiffner, U.; Hoffmann, T.; Kerschbaum, T.; Micheelis, W. Oral health in German children, adolescents, adults and seniorcitizens in 2005. Community Dent. Health 2009, 26, 18-22.

58. Zitzmann, N.U.; Hagmann, E.; Weiger, R. What is the prevalence of various types of prosthetic dental restorations in Europe? Clin. Oral Implant. Res. 2007, 18, 20-33. [CrossRef]

59. Hescot, P.; Bourgeois, D.; Doury, J. Oral health in 35-44 year old adults in France. Int. Dent. J. 1997, 47, 94-99. [CrossRef]

60. Skorupka, W.; Zurek, K.; Kokot, T.; Nowakowska-Zajdel, E.; Fatyga, E.; Niedworok, E.; Muc-Wierzgoń, M. Assessment of oral hygiene in adults. Cent. Eur. J. Public Health 2012, 20, 233-236. [CrossRef]

61. Ozkan, Y.; Özcan, M.; Kulak, Y.; Kazazoglu, E.; Arikan, A. General health, dental status and perceived dental treatment Needs of an elderly population in Istanbul. Gerodontology 2011, 28, 28-36. [CrossRef]

62. Akarslan, Z.Z.; Sadık, B.; Sadık, E.; Erten, H. Dietary habits and oral health related behaviors in relation to DMFT indexes of a group of young adult patients attending a dental school. Med. Oral Patol. Oral Cirurgia Bucal 2008, 13, E800-E807.

63. Drewnowski, A.; Rehm, C.D.; Vieux, F. Breakfast in the United States: Food and nutrient intakes in relation to diet quality in national health and examination survey 2011-2014. A study from the international breakfast research initiative. Nutrients 2018, 10, 1200. [CrossRef]

64. Reeves, S.; Halsey, L.G.; McMeel, Y.; Huber, J.W. Breakfast habits, beliefs and measures of health and wellbeing in a nationally representative UK sample. Appetite 2013, 60, 51-57. [CrossRef] [PubMed]

65. Bi, H.; Gan, Y.; Yang, C.; Chen, Y.; Tong, X.; Lu, Z. Breakfast skipping and the risk of type 2 diabetes: A meta-analysis of observational studies. Public Health Nutr. 2015, 18, 3013-3019. [CrossRef] [PubMed]

66. Nas, A.; Mirza, N.; Hagele, F.; Kahlhofer, J.; Keller, J.; Rising, R.; Kufer, T.A.; Bosy-Westphal, A. Impact of breakfast skipping compared with dinner skipping on regulation of energy balance and metabolic risk. Am. J. Clin. Nutr. 2017, 105, 1351-1361. [CrossRef] [PubMed]

67. Papoutsou, S.; Briassoulis, G.; Wolters, M.; Peplies, J.; Iacoviello, L.; Eiben, G.; Veidebaum, T.; Molnar, D.; Russo, P.; Michels, N.; et al. No breakfast at home: Association with cardiovascular disease risk factors in childhood. Eur. J. Clin. Nutr. 2014, 68, 829-834. [CrossRef]

68. Pengpid, S.; Peltzer, K. The prevalence and social determinants of fruit and vegetable consumption among adults in Kenya: A cross-sectional national population-based survey, 2015. Pan Afr. Med. J. 2018, 31, 137. [CrossRef]

69. Gelibo, T.; Amenu, K.; Tesema, T.; Getinet, M.; Zemedu, T.; Defar, A.; Teklie, H.; Bekele, A.; Shiferaw, F.; Michael, G.A. Low fruit and vegetable intake and its associated factors in Ethiopia: A community based cross sectional NCD steps survey. Ethiop. J. Health Dev. 2017, 31, 355-361.

70. Satheannoppakao, W.; Aekplakorn, W.; Pradipasen, M. Fruit and vegetable consumption and its recommended intake associated with sociodemographic factors: Thailand national health examination survey III. Public Health Nutr. 2009, 12, $2192-2198$. [CrossRef]

71. Dal Moro, J. Dietary habits of older adults: A comparison between two distinct regions of Brazil (Southern and Northeastern). Nutrición Clínica y Dietética Hospitalaria 2015, 35, 26-34. [CrossRef] 